\title{
Dynamic Performance Simulation of Hybrid Excitation Claw-pole Alternator
}

\author{
Jiapeng $\mathrm{Li}^{1}$, Changqing Zhu ${ }^{1, *}$, Min Cong ${ }^{2}$ and Yiming Shen ${ }^{1}$ \\ ${ }^{1}$ School of Electrical Engineering, Shandong University, China \\ ${ }^{2}$ Hefei Power Supply Company, China
}

\begin{abstract}
In order to analyze the dynamic performance of hybrid excitation claw-pole alternator, this paper models and simulates a GA fuzzy self-adaptive PI control system for the alternator based on the derived mathematical equations. According to the simulation results, compared with traditional PID control system, the designed system enables the output voltage to keep steady more quickly and has better adaptive ability.
\end{abstract}

Keywords-hybrid excitation; claw-pole alternator; dynamic performance; GA fuzzy control

\section{INTRODUCTION}

The conventional electric excitation claw-pole alternator (EECPA) are widely used because of their low cost and easy to regulate; however, they suffered from leakage flux, noises, high failure, low efficiency and poor output, which significantly restrict their further development.

The permanent magnet claw-pole alternator (PMCPA) eliminate the field winding, brush and loop, and thus are simpler and more reliable. The efficiency and power density are improved as well since excitation is not required. Unfortunately, the change of either load or speed would cause the frequent instability output voltage of PMCPA, since it is difficult to adjust the magnitude of the air gap magnetic field of PMCPA, which depends on the permanent magnet and permeability, both the application and the development of PMCPA will be restricted in a way $[1,2]$.

Hybrid excitation claw-pole alternator (HECPA) have both permanent magnet and field winding, and the two magnetizations sources are concurrent [3, 4]. Therefore, HECPA takes the advantages of both the EECPA and PMCPA [5]. Hybrid excitation can be utilized to tune the magnet field of PMCPA. By changing excitation current, HECPA with given rotating speed and load scope parameters can achieve stable output voltage. Compared to traditional EECPA, HECPA has high efficiency, low speed and high power density, which makes it a very promising technique in recent years.

In addition, the inductances of the HECPA are highly nonlinear and multi variable coupled. By using a normal PI control this nonlinear characteristic of the HECPA makes it difficult to get satisfied performance such as wide dynamic range, fast response and little overshoot. Thus, we need to adopt other types of controllers capable of taking into account the nonlinearities and adaptable to diverse conditions in real time $[6,7]$.
The mainly purpose of this paper is to analyze the dynamic performance of HECPA by designing a genetic algorithm (GA) fuzzy self-adaptive PI control system for the alternator, which is combined with the GA fuzzy control with reasoning and adaptability and the PI control with high precision. In Section II, the structure of the HECPA will be introduced. In addition, the mathematical equations and global Simulink dynamic simulation model will be presented. Section III constitutes a GA fuzzy self-adaptive PI controller and establishes the control rules for the HECPA. Then, the simulation will be carried out in Section IV. Finally, conclusions will be drawn in Section V.

\section{StRUCtURE AND Model OF the GLOBAL System}

\section{A. Basic Structure}

Figure I shows the diagram of a brushless HECPA introduced in this paper.

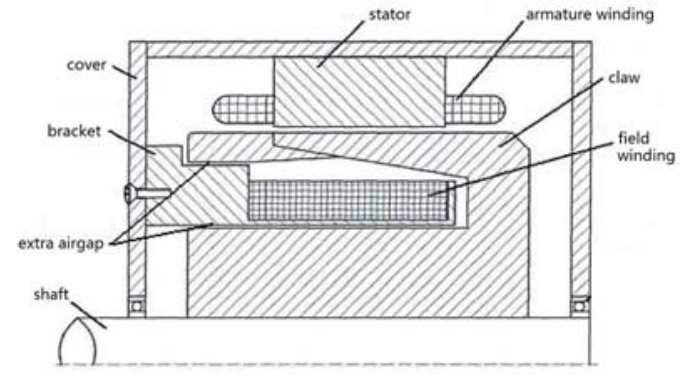

(A) SECTIONAL VIEW

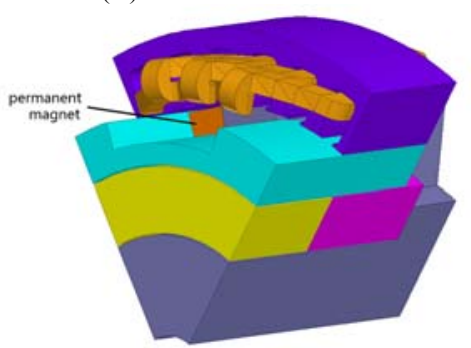

(B) 3D FINITE-ELEMENT MODEL

FIGURE I. DIAGRAM OF THE HECPA.

The introduced brushless HECPA was proposed to overcome the disadvantages of the conventional EECPA and PMCPA. The alternator can be used the main power supply of the vehicle electrical equipment, and it is not only to provide power to the ignition system and other electrical equipment, but 
also to charge the battery $[8,9]$. This HECPA includes stator core, armature windings, claw poles, excitation bracket, DC excitation winding and permanent magnets. The rotor is composed of two claws, and the two claws are welded together with magnetic impermeable material. One claw is fixed on the shaft and the other one has a bore in the claw palm. The excitation bracket is fixed on the end closure, and the excitation winding wraps around the excitation bracket, then the excitation winding and excitation bracket insert into the claw through the bore in the claw palm. There are two additional air gaps between the bracket and the claws.

Compared with the ordinary electric excitation claw-pole alternator, this hybrid excitation brushless claw-pole alternator reduces the excitation loss, increases the alternator's power density, and improves the alternator's low speed power characteristic. Furthermore, its excitation winding is stationary, thus the brush and slip ring can be eliminated. So it has good reliability.

\section{B. Mathematical Model}

According to the Faraday's law, the induced voltages equations can be expressed as

$$
\begin{aligned}
& u_{\mathrm{A}}=\frac{d \psi_{\mathrm{A}}}{d t}-R_{\mathrm{A}} i_{\mathrm{A}} \\
& u_{\mathrm{B}}=\frac{d \psi_{\mathrm{B}}}{d t}-R_{\mathrm{B}} i_{\mathrm{B}} \\
& u_{\mathrm{C}}=\frac{d \psi_{\mathrm{C}}}{d t}-R_{\mathrm{C}} i_{\mathrm{C}}
\end{aligned}
$$

where $R_{\mathrm{A}}, R_{\mathrm{B}}, R_{\mathrm{C}}$ are the stator phase winding resistance, $i_{\mathrm{A}}, i_{\mathrm{B}}$, $i_{\mathrm{C}}$ are the stator phase winding current.

When the flux linkages with armature phases $A, B, C$ and field winding $f$ are expressed in terms of the inductances and currents as follows,

$$
\begin{aligned}
& \psi_{\mathrm{A}}=L_{\mathrm{AA}} I_{\mathrm{A}}+L_{\mathrm{AB}} I_{\mathrm{B}}+L_{\mathrm{AC}} I_{\mathrm{C}}+L_{\mathrm{Af}} I_{\mathrm{f}}+\psi_{\mathrm{APM}} \\
& \psi_{\mathrm{B}}=L_{\mathrm{BA}} I_{\mathrm{A}}+L_{\mathrm{BB}} I_{\mathrm{B}}+L_{\mathrm{BC}} I_{\mathrm{C}}+L_{\mathrm{Bf}} I_{\mathrm{f}}+\psi_{\mathrm{BPM}} \\
& \psi_{\mathrm{C}}=L_{\mathrm{CA}} I_{\mathrm{A}}+L_{\mathrm{CB}} I_{\mathrm{B}}+L_{\mathrm{CC}} I_{\mathrm{C}}+L_{\mathrm{Cf}} I_{\mathrm{f}}+\psi_{\mathrm{CPM}}
\end{aligned}
$$

where two like subscripts denote a self-inductance, and two unlike subscripts denote a mutual inductance between the two windings. The script $L$ is used to indicate that, in general, both the self and mutual inductances of the HECPA, $\Psi_{\mathrm{APM}}, \Psi_{\mathrm{BPM}}$ and $\Psi_{\mathrm{CPM}}$ are the flux linkages generated by the permanent magnets.

The voltage $u_{\mathrm{f}}$ induced by the field winding flux can be expressed as

$$
u_{\mathrm{f}}=\frac{d \psi_{\mathrm{f}}}{d t}+R_{\mathrm{f}} I_{\mathrm{f}}
$$

$$
\psi_{\mathrm{f}}=L_{\mathrm{fA}} I_{\mathrm{A}}+L_{\mathrm{fB}} I_{\mathrm{B}}+L_{\mathrm{fC}} I_{\mathrm{C}}+L_{\mathrm{ff}} I_{\mathrm{f}}+\psi_{\mathrm{fPM}}
$$

where $R_{\mathrm{f}}$ is field resistance, $\Psi_{\mathrm{f}}$ is flux linkage of field winding, and $\Psi_{\mathrm{fPM}}$ is flux linkage which is generated by the permanent magnets, $I_{\mathrm{f}}$ is the dc excitation current. The control system could adjust the $I_{\mathrm{f}}$, thus the HECPA obtains stable output voltage at given rotating speed and load.

The discussion in this paper makes the assumption that the magnetic path is not saturated and the magnetic path is linear. The matrix form of the fundamental equations of this model is as follows,

$$
\begin{aligned}
{\left[\begin{array}{l}
u_{\mathrm{A}} \\
u_{\mathrm{B}} \\
u_{\mathrm{C}}
\end{array}\right]=} & {\left[\begin{array}{ccc}
L_{\mathrm{AA}} & M_{\mathrm{AB}} & M_{\mathrm{AC}} \\
M_{\mathrm{BA}} & L_{\mathrm{BB}} & M_{\mathrm{BC}} \\
M_{\mathrm{CA}} & M_{\mathrm{CB}} & L_{\mathrm{CC}}
\end{array}\right] \cdot \frac{d}{d t}\left[\begin{array}{l}
i_{\mathrm{A}} \\
i_{\mathrm{B}} \\
i_{\mathrm{C}}
\end{array}\right] } \\
& -\left[\begin{array}{ccc}
R_{\mathrm{A}} & 0 & 0 \\
0 & R_{\mathrm{B}} & 0 \\
0 & 0 & R_{\mathrm{C}}
\end{array}\right]\left[\begin{array}{l}
i_{\mathrm{A}} \\
i_{\mathrm{B}} \\
i_{\mathrm{C}}
\end{array}\right]+\left[\begin{array}{l}
e_{\mathrm{A}} \\
e_{\mathrm{B}} \\
e_{\mathrm{C}}
\end{array}\right]
\end{aligned}
$$

where $e_{\mathrm{A}}, e_{\mathrm{B}}, e_{\mathrm{C}}$ is the induced voltage which is generated by both the permanent magnet and the field winding.

\section{Simulation Model}

The dynamic performance simulation model is basically broken up into four sections: the HECPA, rectifier, GA fuzzy self-adaptive PI control system and PWM generator. Figure II shows the global dynamic performance simulation model. The model of the HECPA is established based on the above mathematical equations.

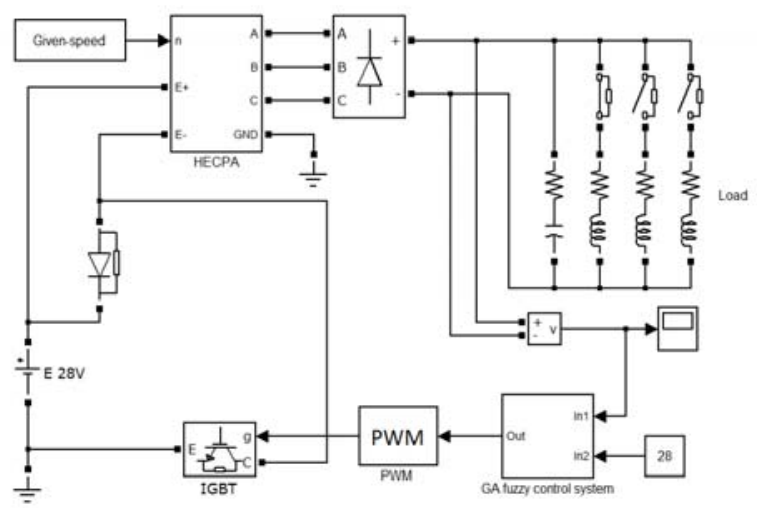

FIGURE II. THE GLOBAL DYNAMIC PERFORMANCE SIMULATION MODEL

\section{GA CONTROL SYSTEM}

\section{A. Fuzzy Control Principle and Rules}

Figure III shows the self-inductance of A phase windings of the introduced HECPA, which is highly nonlinear and multi variable coupled. Fuzzy PI control has been widely used to control ill-defined, nonlinear and other systems. In this paper, 
the fuzzy self-adaptive PI control has been adopted, which is combined with the fuzzy control with reasoning and adaptability and the PI control with high precision.

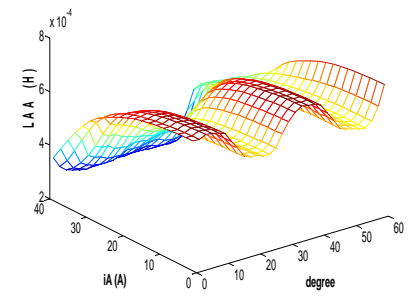

FIGURE III. SELF-INDUCTANCE OF A PHASE WINDINGS

Fuzzy control theory is put forward by American professor Zadeh L A in 1973, and the basic idea of fuzzy control is to use linguistic variables instead of a precise mathematical variables, using the fuzzy relationship instead of precise mathematical relationship, using a simple fuzzy algorithm instead of large and complicated calculation. Fuzzy PI control components four parts: fuzzification, fuzzy inference, fuzzy rules base, and defuzzification [10]. Figure IV shows the structure of the fuzzy control system. The knowledge base consists of the rule base, often expressed in the form of logical implications, such as IFTHEN rules, and the database, containing descriptions of the input and output variables. Fuzzy inference, relating the output actions of the controller with the obtained inputs according to knowledge, makes decisions to obtain fuzzy output variables.

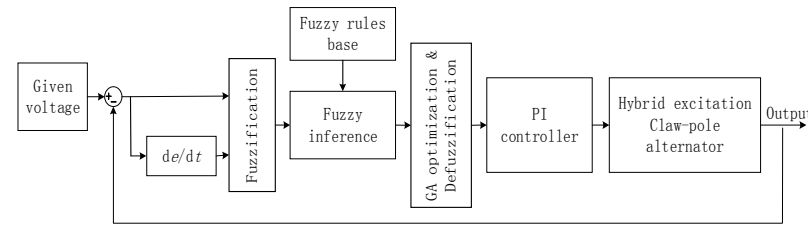

FIGURE IV. STRUCTURE OF FUZZY SELF-ADAPTIVE PI CONTROL SYSTEM

In order to meet the different time input requirements for controller parameters self-adaptive, fuzzy controller with error $e$ and error change rate $e c$ as input, output parameters of PI after through fuzzification, fuzzy inference and deblurring operation, so that can meet different time of $e$ and $e c$ on PI parameters self-adaptive requirements. PI parameters could be modified by the fuzzy control part on-line.

In this system, $e$ and $e c$ are input variables, where $e$ and $e c$ stand for error and error change fuzzy values [11], whose universes of discourse are $\{-6,-5,-4,-3,-2,-1,0,1,2,3,4$, $5,6\}$ and fuzzy subsets assume $\{\mathrm{NB}, \mathrm{NM}, \mathrm{NS}, \mathrm{ZO}, \mathrm{PS}, \mathrm{PM}$, $\mathrm{PB}\}$, respectively. The basic domain of $\Delta k p$ and $\Delta k i$ is $\{-3,-2$, $-1,0,1,2,3\}$. The symbol $\mathrm{N}$ stands for negative, $\mathrm{P}$ for positive, $\mathrm{ZO}$ for zero, $\mathrm{B}$ for big, $\mathrm{M}$ for middle, $\mathrm{S}$ for small. The corresponding membership functions are shown in Figure V.

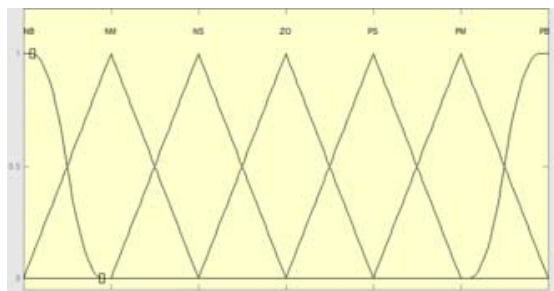

(A) MEMBERSHIP FUNCTION OF E AND EC

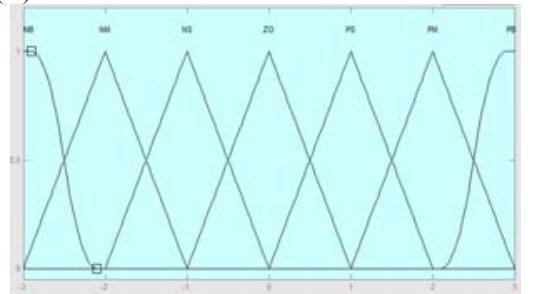

(B) MEMBERSHIP FUNCTION OF $\triangle K P$ AND $\triangle K I$

FIGURE V. MEMBERSHIP FUNCTION OF $E, E C, \triangle K P$ AND $\triangle K I$

Fuzzy rules is the core of a fuzzy controller [12, 13], and its role is to adjust PI parameters in real time, so the establishment of fuzzy rules is directly related to the control effect of the whole control system. The fuzzy rule is work out by designers and engineers of design experience and long-term work summary. The fuzzy control rules of $\Delta k p$ and $\Delta k i$ applied in this paper is shown in Tables I and II.

TABLE I. FUZZY CONTROL RULES OF $\triangle K P$

\begin{tabular}{|c|c|c|c|c|c|c|c|}
\hline $\begin{array}{c}\text { ec } \\
\boldsymbol{e}\end{array}$ & NB & NM & NS & ZO & PS & PM & PB \\
\hline NB & PB & PB & PM & PM & PS & ZO & ZO \\
\hline NM & PB & PB & PM & PS & PS & ZO & NS \\
\hline NS & PM & PM & PM & PS & ZO & NS & NS \\
\hline ZO & PM & PM & PS & ZO & NS & NM & NM \\
\hline PS & PS & PS & ZO & NS & NS & NM & NM \\
\hline PM & PS & ZO & NS & NM & NM & NM & NB \\
\hline PB & ZO & ZO & NM & NM & NM & NB & NB \\
\hline
\end{tabular}

TABLE II. FUZZY CONTROL RULES OF $\triangle K I$

\begin{tabular}{|c|c|c|c|c|c|c|c|}
\hline $\begin{array}{c}\boldsymbol{e c} \\
\boldsymbol{e}\end{array}$ & NB & NM & NS & ZO & PS & PM & PB \\
\hline NB & NB & NB & NM & NM & NS & ZO & ZO \\
\hline NM & NB & NB & NM & NS & NS & ZO & ZO \\
\hline NB & NB & NM & NS & NS & ZO & PS & PS \\
\hline ZO & NM & NM & NS & ZO & PS & PM & PM \\
\hline PS & NM & NS & ZO & PS & PS & PM & PB \\
\hline PM & ZO & ZO & PS & PS & PM & PM & PB \\
\hline PB & ZO & ZO & PS & PM & PM & PB & PB \\
\hline
\end{tabular}

\section{B. GA Optimization of the Fuzzy Control System}

The fuzzy control rules are uncertain because of the control target is high nonlinear. Even if engineers get the fuzzy control rules under some certain conditions, the rules may be changed as the target varying. In this study, genetic algorithm is used to optimize the inference rules. Table III and Table IV show the fuzzy control rules intimidated through GA method. Through the optimization, 12 rules are eliminated and 8 rules are optimized. The output surface of the $\Delta k p$ based on the fuzzy optimized control rules is shown in Figure VI. 
TABLE III. FUZZY CONTROL RULES OF $\triangle K P$ AFTER OPTIMIZATION

\begin{tabular}{|c|c|c|c|c|c|c|c|}
\hline $\begin{array}{l}\text { ec } \\
\text { e }\end{array}$ & NB & NM & NS & ZO & PS & PM & PB \\
\hline NB & PB & PB & PM & & PS & ZO & ZO \\
\hline NM & & PM & PS & PS & PS & ZO & NS \\
\hline NS & PM & PM & PM & PS & ZO & NS & NS \\
\hline ZO & PM & PM & PS & ZO & NS & NM & NM \\
\hline PS & & PS & ZO & NS & NS & NM & \\
\hline PM & PS & ZO & ZO & NM & NM & NB & NB \\
\hline PB & ZO & & NM & & NM & NB & NB \\
\hline
\end{tabular}

TABLE IV. FUZZY CONTROL RULES OF $\Delta K I$ AFTER OPTIMIZATION

\begin{tabular}{|c|c|c|c|c|c|c|c|}
\hline $\begin{array}{l}\text { ec } \\
\text { e }\end{array}$ & NB & NM & NS & ZO & PS & PM & PB \\
\hline NB & NB & NB & NM & & NS & ZO & ZO \\
\hline NM & & NM & NS & NS & NS & ZO & ZO \\
\hline NB & NB & NM & NS & NS & ZO & PS & PS \\
\hline ZO & NM & NM & NS & ZO & PS & PM & PM \\
\hline PS & & NS & ZO & PS & PS & PM & \\
\hline PM & ZO & ZO & ZO & PS & PM & PB & PB \\
\hline PB & ZO & & PS & & PM & PB & PB \\
\hline
\end{tabular}

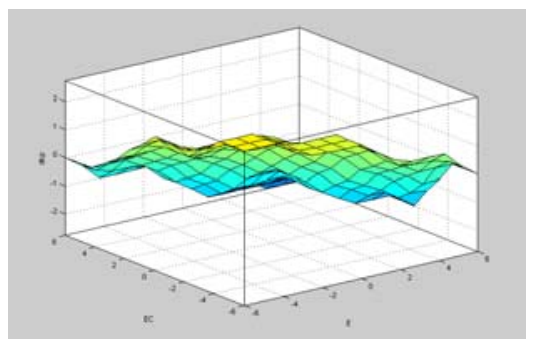

FIGURE VI. OUTPUT SURFACE OF THE $\triangle$ KP

In order to improve the dynamic performance of the excitation control system, the elements of the query table need to be adjusted according to the input variables. To do this, this paper adjusts the coefficients $\left(K_{\mathrm{e}}, K_{\mathrm{ec}}, K_{\mathrm{uP}}\right.$ and $\left.K_{\mathrm{uI}}\right)$ to tuning the control system on-line. The adjust function as follows

$$
\begin{gathered}
K_{\mathrm{e}}=\left\{\begin{array}{l}
K_{\mathrm{e}(0)}+\lambda_{1} \times \frac{e_{\max }}{2},|e|>\frac{e_{\max }}{2} \\
K_{\mathrm{e}(0)}+\lambda_{1} \times|e|,|e| \leq \frac{e_{\text {max }}}{2}
\end{array}\right. \\
K_{\mathrm{ec}}=\left\{\begin{array}{l}
K_{\mathrm{ec}(0)}+\lambda_{2} \times \frac{e_{\max }}{2},|e|>\frac{e_{\max }}{2} \\
K_{\mathrm{ec}(0)}+\lambda_{2} \times|e|,|e| \leq \frac{e_{\max }}{2}
\end{array}\right. \\
K_{\mathrm{uP}}=\left\{\begin{array}{l}
K_{\mathrm{uP}(0)}+\lambda_{3} \times \frac{e_{\max }}{2},|e|>\frac{e_{\max }}{2} \\
K_{\mathrm{uP}(0)}+\lambda_{3} \times|e|,|e| \leq \frac{e_{\max }}{2}
\end{array}\right.
\end{gathered}
$$

$$
K_{\mathrm{uI}}=\left\{\begin{array}{l}
K_{\mathrm{uI}(0)}+\lambda_{4} \times \frac{e_{\max }}{2},|e|>\frac{e_{\max }}{2} \\
K_{\mathrm{uI}(0)}+\lambda_{4} \times|e|,|e| \leq \frac{e_{\max }}{2}
\end{array}\right.
$$

where $K_{\mathrm{e}(0)}, K_{\mathrm{ec}(0)}, K_{\mathrm{uP}(0)}$ and $K_{\mathrm{ul}(0)}$ are reference values; $\lambda_{1}, \lambda_{2}, \lambda_{3}$ and $\lambda_{4}$ are tuning parameters; $e_{\max }$ is the maximum of the basic domain for the error.

When the coefficients are optimized by the genetic algorithm, adaptability function $f$ is the crux of the matter. The function could be described as

$$
\begin{aligned}
f=\alpha \exp & {\left[-\left(\frac{M_{\mathrm{P}}}{M_{\mathrm{P}}^{\prime}}\right)^{2}\right]+\beta \exp \left[-\left(\frac{t_{\mathrm{s}}}{t_{\mathrm{s}}^{\prime}}\right)^{2}\right] } \\
& +\eta \exp \left[-\left(\frac{e_{\mathrm{ss}}}{e_{\mathrm{ss}}^{\prime}}\right)^{2}\right]
\end{aligned}
$$

where $M_{\mathrm{P}}$ is the maximum of overshoot; $t_{\mathrm{s}}$ is the setting time; $e_{\mathrm{ss}}$ is the steady-state error; $M_{\mathrm{P}}{ }^{\prime}, t_{\mathrm{s}}{ }^{\prime}$ and $e_{\mathrm{ss}}{ }^{\prime}$ are the corresponding expected value; $\alpha, \beta$ and $\eta$ are the weight coefficient.

\section{Dynamic Performance Simulation}

Based on the above developed model, the steady-state and dynamic performances of a $28 \mathrm{~V}$ HECPA are simulated. The PWM generator's duty cycle is regulated by the chopper circuit. The resistances and inductances of the alternator are calculated by finite-element analysis. The output voltage could be controlled to a stable level by changing the excitation current, though the HECPA's rotating speed may fluctuate. Figure VII shows the waveform of given speed. Figure VIII shows the waveform of excitation current. The waveform of output voltage both under the GA fuzzy control and traditional PID control is shown in Figure IX.

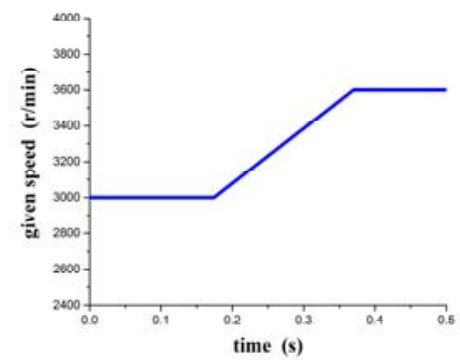

FIGURE VII. WAVEFORM OF GIVEN SPEED 


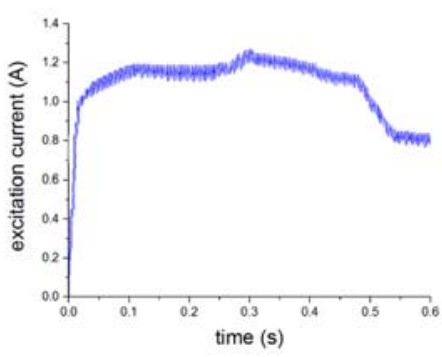

FIGURE VIII. WAVEFORM OF THE EXCITATION CURRENT

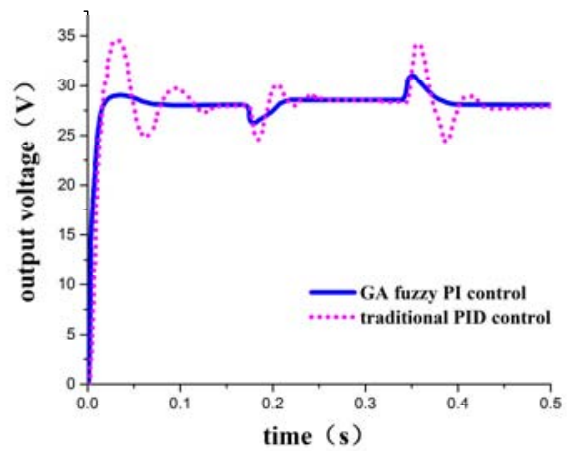

FIGURE IX. OUTPUT VOLTAGE WAVEFORM WHEN CHANGING THE SPEED

Similarly, after the waveform is stable, subtract twenty percent load at 0.6 second and plus twenty percent load when 0.9 second. The waveform comparison is shown in Figure X.

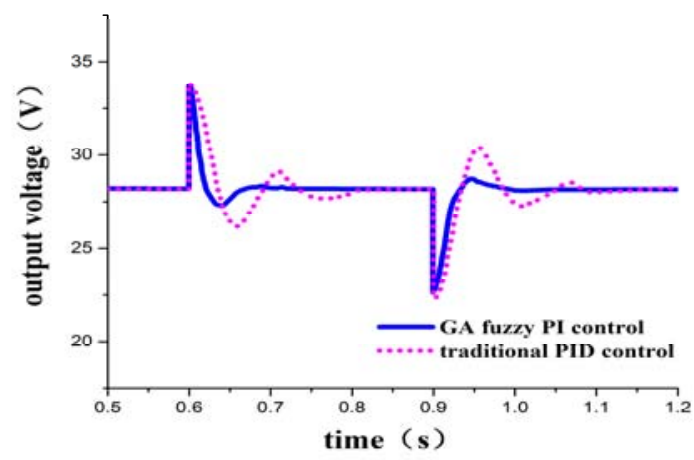

FIGURE X. OUTPUT VOLTAGE WAVEFORM WHEN CHANGING THE LOAD

It can be seen from the results that the GA fuzzy selfadaptive control system can make the output voltage quickly reached the steady-state $28 \mathrm{~V}$ by changing the excitation current.

\section{CONCLUSIONS}

In this paper, the basic structure of a brushless HECPA has been introduced at first. The global simulation model of the HECPA has been presented used the MATLAB/Simulink based on the derived mathematical model of this alternator. The inductances of the HECPA are highly nonlinear and multi variable coupled. By using a normal PI control this nonlinear characteristic of the HECPA makes it difficult to get satisfied performance such as wide dynamic range, fast response and little overshoot. Therefore, we designed a GA fuzzy selfadaptive PI control system for the HECPA. It can be seen that by changing the excitation current the fuzzy self-adaptive control system can make the output voltage quickly reached the steady-state $28 \mathrm{~V}$ compared with traditional PID control. The dynamic performance simulation results show that the HECPA with the designed control system has good ability in robustness, real time performance and stability.

\section{ACKNOWLEDGMENT}

This work was supported by the National Natural Science Foundation of China under Project 51177090.

\section{REFERENCES}

[1] R. Tang, Theory and Design of Modern Permanent Magnet Motors. BeiJing: China Machine Press, 2000.

[2] Y. Amara, L. Vido, M. Gabsi, E. Hoang, B. A. A. Hamid, and M. Lecrivain, "Hybrid Excitation Synchronous Machines: Energy-Efficient Solution for Vehicles Propulsion," IEEE Transactions on Vehicular Technology, vol. 58, pp. 2137-2149, 2009.

[3] W. Li and S. Huang, "Analysis and Design of Hybrid Excitation Clawpole Generator," Electric Power Components \& Systems, vol. 39, pp. 680-695, 2011

[4] X. Fu and J. Zou, "Design and analysis of a novel hybrid excitation synchronous generator," in 3rd IEEE Conference on Industrial Electronics and Applications Singapore, 2008, pp. 2074-7.

[5] Y. Amara, L. Vido, M. Gabsi, E. Hoang, A. Hamid Ben Ahmed, and M. Lecrivain, "Hybrid Excitation Synchronous Machines: Energy-Efficient Solution for Vehicles Propulsion," IEEE Transactions on Vehicular Technology, vol. 58, pp. 2137-2149, 2009.

[6] L. Wang, M. Tian and Y. Gao, "Fuzzy Self-adapting PID Control of PMSM Servo System," in Electric Machines \& Drives Conference, 2007. IEMDC '07. IEEE International, 2007, pp. 860-863.

[7] K. Tanaka and M. Sugeno, "Stability analysis and design of fuzzy control systems," in Networking, Sensing and Control, 2008. ICNSC 2008. IEEE International Conference on, 2008, pp. 1721-1725.

[8] D. W. Qiao, X. H. Wang and C. Q. Zhu, "Study on a hybrid excitation brushless claw-pole alternator with an annular PM between the claw poles," Dianji Yu Kongzhi Xuebao/electric Machines \& Control, vol. 18, pp. 30-35, 2014.

[9] D. Qiao, X. Wang and C. Zhu, "3-D finite element investigation of flux regulation performance of a novel hybrid excitation brushless claw-pole alternator," in Advanced Materials Research, Jilin, China, 2013, pp. 1226-1229.

[10] C. Ming, S. Qiang and E. Zhou, "New self-tuning fuzzy PI control of a novel doubly salient permanent-magnet motor drive," IEEE Transactions on Industrial Electronics, vol. 53, pp. 814-21, 2006.

[11] B. Youn and D. Sun, "Fuzzy PID Control Technology for Synchronous Generator Excitation," International Journal of Control and Automation, vol. 8, pp. 91-98, 2015-10-312015.

[12] R. Ramya and K. Selvi, "A simple fuzzy excitation control system for synchronous generator," in Emerging Trends in Electrical and Computer Technology (ICETECT), 2011 International Conference on, 2011, pp. 35 $-39$.

[13] N. X. Truong, H. Wang and N. V. Ngu, "Research on fuzzy PI control for switched reluctance wind power inverter with SVPWM," in Remote Sensing, Environment and Transportation Engineering (RSETE), 2011 International Conference on, 2011, pp. 4342-4345. 